\title{
Incompatible effects of p53 and HDAC inhibition on p21 expression and cell cycle progression
}

\author{
MCC Sachweh ${ }^{1}$, CJ Drummond ${ }^{1}$, M Higgins ${ }^{2}$, J Campbell ${ }^{2}$ and S Laín ${ }^{*, 1,2}$
}

Nutlin-3 selectively activates $\mathrm{p} 53$ by inhibiting the interaction of this tumor suppressor with its negative regulator murine double minute 2 (mdm2), while trichostatin A (TSA) is one of the most potent histone deacetylase (HDAC) inhibitors currently available. As both Nutlin-3 and TSA increase the levels of the cell cycle inhibitor p21(cip1/waf1) in cells, we investigated whether a combination of these compounds would further augment p21 levels. Contrary to expectations, we found that short-term exposure to Nutlin-3 and TSA in combination did not have an additive effect on p21 expression. Instead, we observed that activation of p53 prevented the ability of TSA to increase p21 levels. Furthermore, TSA inhibited Nutlin-3-induced expression of p53-dependent mRNAs including P21. This negative effect of TSA on Nutlin-3 was significantly less pronounced in the case of hdm2, another p53 downstream target. Aside from suggesting a model to explain these incompatible effects of Nutlin-3 and TSA, we discuss the implications of our findings in cancer therapy and cell reprogramming.

Cell Death and Disease (2013) 4, e533; doi:10.1038/cddis.2013.61; published online 7 March 2013

Subject Category: Cancer

Small-molecule murine double minute 2 (mdm2)/p53 binding antagonists and histone deacetylase (HDAC) inhibitors are currently in clinical trials for cancer, and HDAC inhibitor suberoylanilide hydroxamic acid (SAHA; vorinostat; Zolinza) has been approved for the treatment of cutaneous T-cell lymphoma. ${ }^{1}$

Nutlin-3 is the most well-characterized mdm2/p53-binding antagonist. It binds to one of two sites in $\mathrm{mdm} 2$ occupied by the tumor suppressor p53 and protects the latter from mdm2mediated degradation. As a consequence, Nutlin-3 selectively promotes cell cycle arrest and apoptosis in cells expressing wild-type $p 53 .{ }^{2}$ The activation of a variety of p53-dependent genes, including CDKN1A encoding p21(waf1/cip1) and PIG3, by Nutlin-3 is thought to mediate the majority of effects of this compound on cell proliferation and viability. ${ }^{3}$ However, Nutlin-3 is particularly effective at inducing the expression of MDM2, which is also a p53-dependent gene. The binding of Nutlin-3 to the mdm2 protein also protects mdm2 from degradation and stabilizes the structure of $\mathrm{mdm} 2$. Moreover, we have shown that following the removal of Nutlin-3 from cell cultures, p53 protein disappears within $30 \mathrm{~min}$, while $\mathrm{mdm} 2$ levels remain constant for at least $3 \mathrm{~h} .{ }^{4}$ Altogether, these results suggest that achieving a cytotoxic response following p53 reactivation may be difficult with $\mathrm{mdm} 2 / \mathrm{p} 53$-binding antagonists.
Trichostatin A (TSA) is a natural compound and one of the most potent inhibitors of HDACs in both biochemical and cellular assays. TSA inhibits a wide range of HDACs, including all members of class I and II HDACs. Treatment with TSA for $24 \mathrm{~h}$ or longer has been reported to increase p53 acetylation and in this way protects p53 from degradation. In contrast, TSA has also been shown to reduce p53 expression by decreasing p53 promoter activity or even destabilization of P53 mRNA. ${ }^{5,6}$ TSA and other HDAC inhibitors, including SAHA, do increase the expression of p21. However, unlike Nutlin-3, this activation of p21 expression is independent of the p53 status in cells. ${ }^{7-12}$

With the purpose of enhancing the activity of $p 53$, we have combined Nutlin-3 with a number of p53-modulating compounds. Here we present the data obtained using a combination of Nutlin-3 and TSA in different cell lines.

\section{Results}

TSA reduces the induction of p53-dependent genes by Nutlin-3. As a first approach to analyze whether Nutlin-3 and TSA cooperate in promoting p53-dependent transactivation, we tested their effects on an artificial p53-responsive reporter. In particular, we used ARN8 and MCF7 cells harboring wild-type p53 and a construct encoding the $L A C Z$ gene under the control of a p53-responsive promoter. As

\footnotetext{
${ }^{1}$ Department of Microbiology, Tumor and Cell Biology, Karolinska Institutet, Stockholm 171 77, Sweden and ${ }^{2}$ Centre for Oncology and Molecular Medicine, University of Dundee, Ninewells Hospital and Medical School, Dundee, Tayside DD1 9SY, UK

*Corresponding author: S Laín, Department of Microbiology, Tumor and Cell Biology, Karolinska Institutet, Nobels väg 16, Stockholm 171 77, Sweden. Tel: +46 (0)8 524 84603; Fax: +46 (0)8 304276; E-mail: sonia.lain@ki.se

Keywords: trichostatin A; Nutlin-3; p53; p21; cancer therapy; iPS cell generation

Abbreviations: $\beta$-gal, $\beta$-galactosidase; BrdU, 5-bromo-2'-deoxyuridine; BSA, bovine serum albumin; CPRG, chlorophenol red- $\beta$-D-galactopyranoside; DMSO, dimethyl sulfoxide; EtOH, ethanol; GAPDH, glyceraldehyde 3-phosphate dehydrogenase; HDAC, histone deacetylase; HDM2, human MDM2; HNDFs, human normal dermal fibroblasts; HRP, horseradish peroxidase; iPS cell, induced pluripotent stem cell; KLF4, Krüppel-like factor 4; MDM2, murine double minute 2; OCT4, octamerbinding transcription factor 4; PI, propidium iodide; P/S, penicillin/streptomycin; RNase A, ribonuclease A; RT, room temperature; RT-PCR, reverse transcriptionpolymerase chain reaction; SAHA, suberoylanilide hydroxamic acid; SOX2, SRY (sex determining region Y)-box 2; TSA, trichostatin A

Received 23.7.12; revised 06.12.12; accepted 01.2.13; Edited by D Aberdam
} 
expected, Nutlin-3 on its own increased p53-dependent transcription, whereas TSA had no positive effect (Figure 1). Unexpectedly, when Nutlin-3 and TSA were combined, p53 reporter activity was reduced, suggesting that TSA has a negative effect on Nutlin-3-induced p53 transcription factor function.

We then analyzed the effects of Nutlin-3, TSA and their combination on mRNA expressed from p53 downstream target genes in MCF-7 cells (Figures $2 a$ and $c$ and Supplementary Figure S1A). Nutlin-3 increased the expression of p53-dependent mRNAs following $5 \mathrm{~h}$ of exposure. TSA on its own induced an increase in P21 mRNAs as well as a small but reproducible rise in HDM2 (human MDM2) mRNA. In contrast, pre-treatment of cells with TSA clearly reduced P21 and PIG3 mRNA levels in Nutlin-3-treated cells. This negative effect of TSA on Nutlin-3 activation of HDM2 mRNA expression was less evident. Interestingly, the expression of the proapoptotic gene NOXA, which was identified as being p53-dependent, ${ }^{13}$ was increased by TSA regardless of the presence of Nutlin-3. This suggests that TSA does not reduce mRNA levels of all genes. Supporting this, TSA also had a positive effect on luciferase reporter expression (Figure 1b).

In MCF7 cells, the induction of p21 protein by Nutlin-3 was reduced when cells were pre-treated with TSA, although to a lesser extent than P21 mRNA levels (Figure 2b and Supplementary Figure S2A). The induction of pig3 at the protein level by short exposure to Nutlin-3 was very weak. Even so, TSA caused a slight reduction in Nutlin-3-induced pig3 protein levels. Hdm2 protein levels were highly induced by Nutlin-3, and this induction was insensitive to TSA pretreatment. Noxa protein levels were clearly increased by TSA in the presence or absence of Nutlin-3.

Similar results were obtained in human normal dermal fibroblasts (HNDFs) (Figure 3 and Supplementary Figures S1B and S2B), although TSA on its own did not raise HDM2 mRNA levels and there was no negative effect of TSA on Nutlin-3 activation of HDM2 mRNA expression.

Short-term TSA treatment leads to a small reduction in P53 mRNA levels but not in p53 protein levels. In MCF7 cells, P53 mRNA levels were insensitive to Nutlin-3 and slightly reduced by TSA on its own as well as in the presence of Nutlin3 (Figure 2c). This is in line with reports showing that TSA reduces P53 mRNA expression and/or the stability of P53 mRNA. ${ }^{5,6}$ However, p53 protein levels were not reduced in response to short-term treatment with TSA in any of the conditions tested and regardless of the anti-p53 antibody used (Supplementary Figure S3). In addition, we did not detect changes in p53's subcellular localization induced by TSA

Figure 1 TSA reduces p53-dependent transcription in Nutlin-3-treated cells. (a) ARN8 melanoma cells containing wild-type p53 and the p53-dependent $\triangle$ Fos-RGC-LacZ reporter plasmid were treated with TSA and/or Nutlin-3 $(2 \mu \mathrm{M})$ for $16 \mathrm{~h}$ as indicated. $\beta$-Gal p53 reporter activity (top panel) and protein content (bottom panel) were measured. (b) MCF7 cells transiently transfected with the p53-dependent $\triangle$ Fos-RGC-LacZ reporter plasmid together with a control plasmid expressing firefly or Renilla luciferase under the control of the SV40 promoter. At $24 \mathrm{~h}$ post-transfection, cells were treated with TSA and/or Nutlin-3 $(5 \mu \mathrm{M})$ for $16 \mathrm{~h}$ as indicated and reporter activities measured. Error bars represent standard deviation
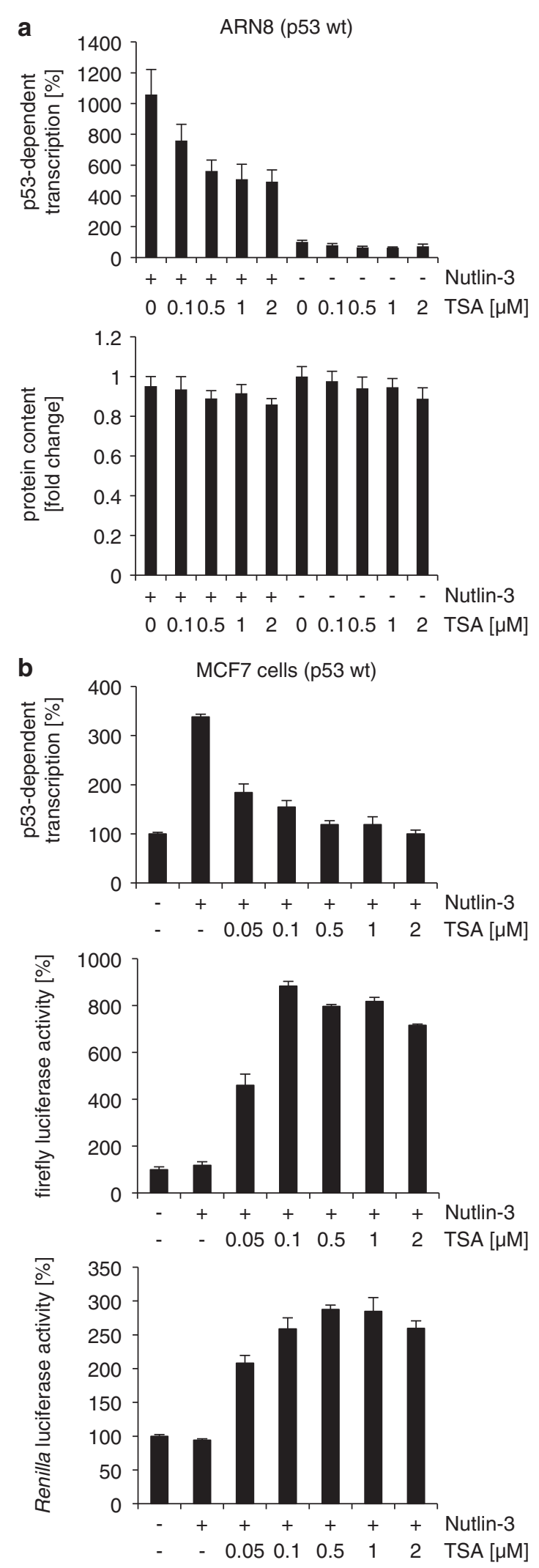

Cell Death and Disease 
a
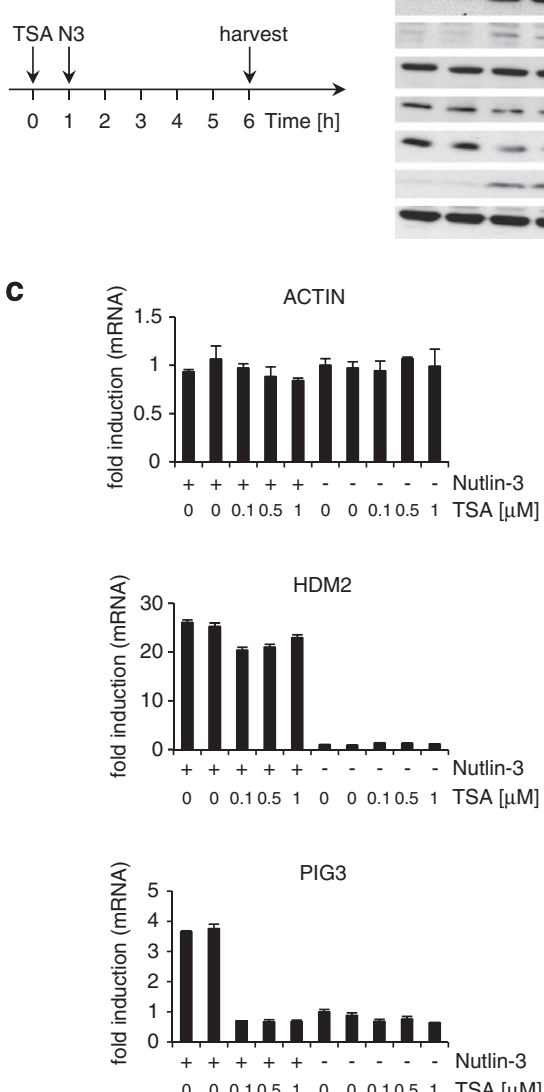

b

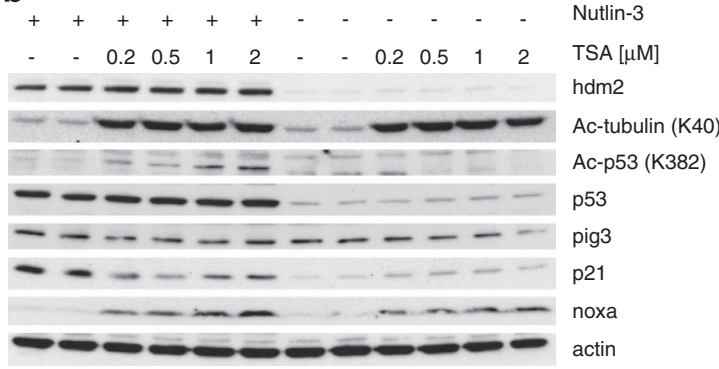

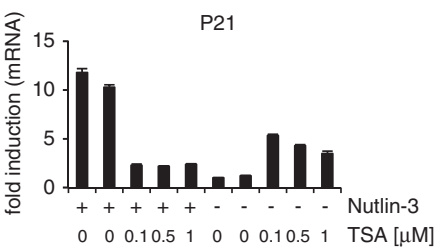

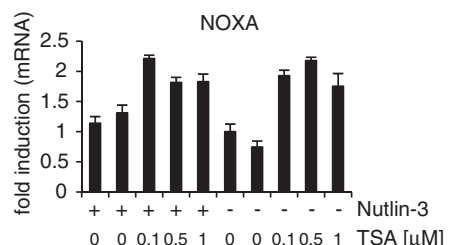

Figure 2 Effects of TSA pre-treatment on the expression of Nutlin-3-responsive genes in MCF7 tumor cells. (a) Cells were mock-treated (ethanol (EtOH)) or treated with TSA at various concentrations for $6 \mathrm{~h}$; $1 \mathrm{~h}$ after TSA treatment, Nutlin-3 $(5 \mu \mathrm{M})$ or vehicle control (dimethyl sulfoxide (DMSO) or EtOH) was added. Target gene expression was determined by (b) western blotting and (c) quantitative RT-PCR. (b) Acetylated $\alpha$-tubulin (K40) was used as control for TSA's activity and actin as a loading control. (c) Error bars represent standard deviation. Graphs shown are representative of three independent experiments; the other two sets of data are shown in Supplementary Figure S1A

(Supplementary Figures S3 and S4). Instead, acetylation of p53 at residue $\mathrm{K} 382$, which is associated with p53 stabilization, was increased by TSA in combination with Nutlin-3 (Figure 2b). Similar results were obtained in HNDF cells (Figure 3 ).

TSA weakens Nutlin-3-induced G1 arrest. Nutlin-3 treatment is known to cause cell cycle arrest in cells expressing wild-type p53 and this effect is highly dependent on its ability to increase p21 expression. ${ }^{14}$

As shown in Figure 4 and Supplementary Figure S5, in MCF-7 cells, even a short exposure to Nutlin-3 led to an increase in the proportion of $\mathrm{G} 1$-phase cells $(P<0.005)$ and a reduction in early $S$-phase cells $(P<0.0001)$. Interestingly, if cells were pre-treated with TSA, this Nutlin-3-induced reduction in early $S$-phase cells was less apparent $(P<0.0001)$. Note that TSA increased the proportion of early S-phase cells also in the absence of Nutlin-3 $(P<0.005)$. These observations show that in the short term, TSA can prevent Nutlin-3-induced G1 arrest. This is in agreement with previous reports of the positive effect of TSA on the S-phase entry. ${ }^{15,16}$ p53 reduces TSA's ability to activate p21 expression. It is well established that TSA increases p21 expression independently of p53. ${ }^{7-10}$ Indeed, a short treatment with TSA markedly increased P21 mRNA and protein levels in MDA-MB-468 cells carrying mutant p53 (Supplementary Figure S6). Our previous experiments have shown that TSA can activate p21 expression in cells retaining wild-type p53 (Figures 2 and 3 and Supplementary Figures S1 and S2). However, at least at the protein level, we noticed that the effect of TSA in these cells was much weaker than in MDAMB-468 cells. This suggests that wild-type p53 prevents p21 induction by TSA. To confirm this, we used HCT116 p53 $3^{+/+}$ and HCT116 $\mathrm{p5}^{-/-}$isogenic cell lines. TSA led to a much stronger increase in P21 mRNA and protein levels in

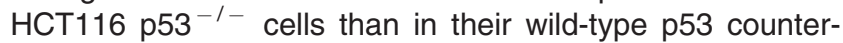
parts (Figure 5 and Supplementary Figures S1C, S1D and S2C, S2D).

In a series of transfection assays, we observed that in the presence of transfected $\mathrm{p53}$, TSA had a negative effect on p21 expression (Figure 6). Furthermore and as expected, this negative effect was weakened when hdm2 


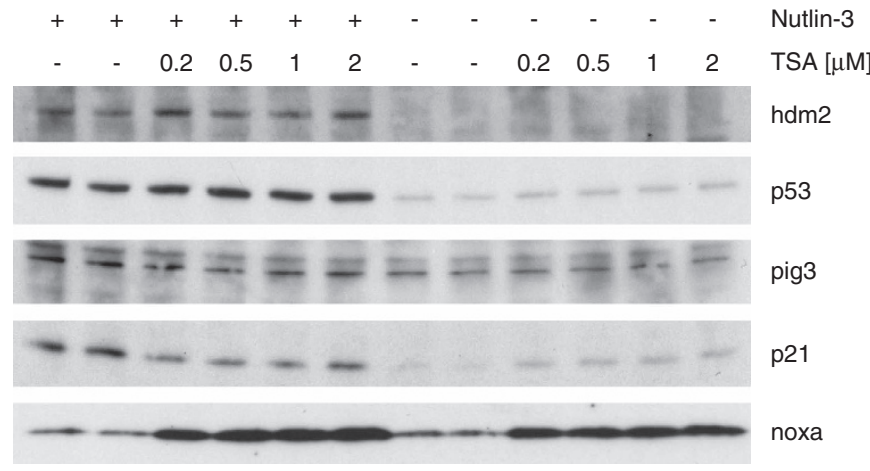

b
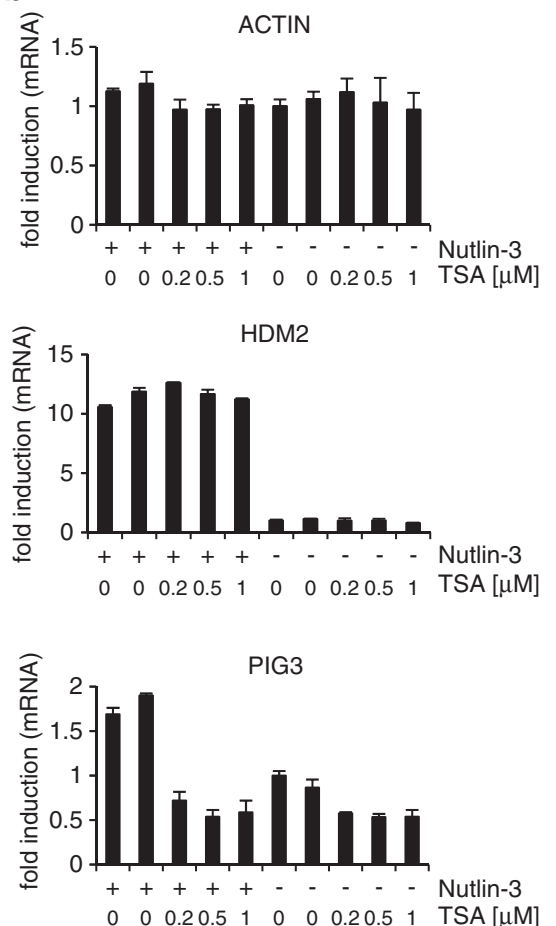
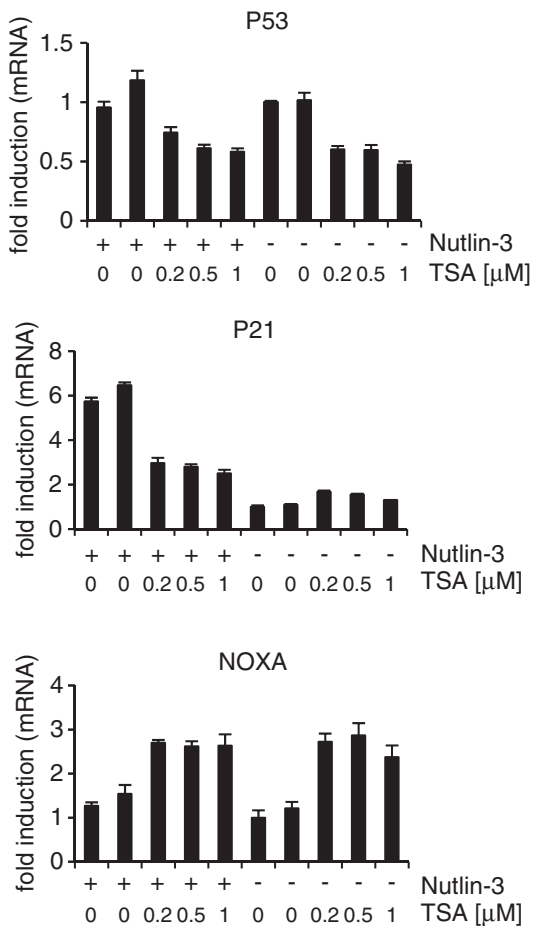

Figure 3 Effects of TSA pre-treatment on the expression of Nutlin-3-responsive genes in HNDFs. Samples were treated and analyzed as in Figure 2. Error bars represent standard deviation. Graphs shown are representative of three independent experiments; the other two sets of data are shown in Supplementary Figure S1B

was coexpressed. Altogether, these results show that active p53 has a negative effect on TSA's ability to induce p21.

We also determined at what phase in the cell cycle p21 is induced by TSA or Nutlin-3. As shown in Figure 7, Nutlin-3 increased p21 protein levels in all phases of the cell cycle, whereas TSA increased p21 only in G1 and G2 phases. Therefore, it is unlikely that the reciprocal negative effects of TSA and Nutlin-3 on p21 expression are due to cell cycle arrest at a stage where $\mathrm{p} 21$ cannot be induced by one of these compounds.

p53 activation by Nutlin-3 reduces TSA's ability to cause G2/M arrest and endoreduplication in tumor cells. Longterm treatment with TSA can lead to an arrest of cells in the G2 or G2/M phase of the cell cycle. ${ }^{17,18}$ In agreement with this, after longer exposure to TSA ( $30 \mathrm{~h})$, the great majority of cells in the culture had a 4 N DNA content (Figure 8a). TSAinduced $\mathrm{G} 2 / \mathrm{M}$ arrest and endoreduplication occurred in HCT116 cells regardless of whether they contain wild-type p53 or not. However, both the G2/M arrest and the endoreduplication events were reduced in cells pre-treated with Nutlin-3. As expected, this protective effect of Nutlin-3 was restricted to cells that express wild-type p53 (Figures 8a and b).

Nevertheless, as shown in a clonogenic assay (Figure 8c), cotreatment of HCT116 p53 $3^{+/+}$cells with Nutlin-3 and TSA is more toxic than either treatment on its own. Therefore, in the long term, Nutlin-3 does not substantially protect tumor cells from toxicity induced by TSA. In contrast, Nutlin-3 is known to

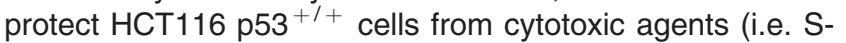
and $\mathrm{M}$-phase inhibitors) very effectively. ${ }^{19-23}$ 


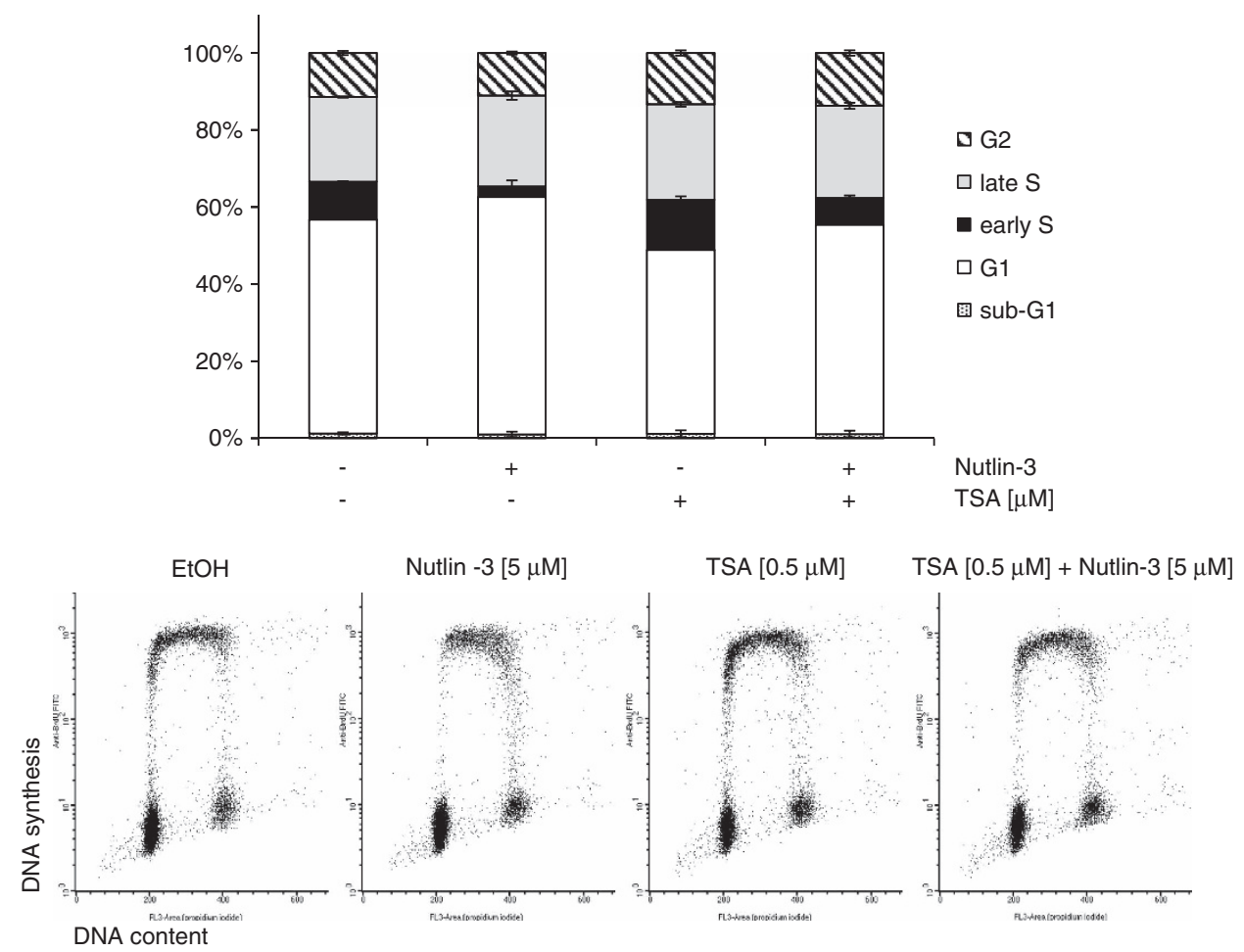

Figure 4 TSA weakens Nutlin-3-induced G1 arrest. MCF7 cells were treated as in Figure 2a. Samples were subjected to two-dimensional flow cytometric analysis following staining with $\mathrm{BrdU}$ and PI. Error bars represent standard deviation $(n=4)$

\section{Discussion}

We sought to identify small molecules that could enhance the activity of $\mathrm{p} 53$ by combining the $\mathrm{mdm} 2 / \mathrm{p} 53$-binding antagonist Nutlin-3 with small molecules known to modulate p53 function. One of the compounds tested was TSA, which is known to affect p53 expression as well as its stability. Contrary to our initial expectations from experiments performed by long-term treatment of cells with TSA in other labs, our results clearly showed that short-term treatment with this HDAC inhibitor reduced the expression of p53 transcription factor function. In addition, activated p53 reduced the ability of TSA to induce p21 expression. In the next paragraphs, we propose a series of explanations for the observed effects of the short-term cotreatment with TSA and Nutlin-3 on the expression of hdm2, p21 and pig3.

TSA has a minor effect on hdm2 expression. In the absence of Nutlin-3, TSA did not have a substantial negative effect on HDM2 mRNA levels, whereas in the presence of Nutlin-3, TSA reduced HDM2 mRNA levels to a small extent in some cell lines (i.e. MCF7 and HCT116 p53 ${ }^{+/+}$, see Figure 2 and Supplementary Figure S7). This small reduction in HDM2 mRNA levels could be explained by the small TSAinduced decrease in P53 mRNA observed in these cells. In HNDFs cotreated with TSA and Nutlin-3, there was no reduction in HDM2 mRNA levels in response to TSA, even when P53 mRNA levels were reduced by TSA (Figure 3). The lack of effect on HDM2 mRNA levels in HNDF cells may be related to the ability of TSA to induce the expression of p14 ${ }^{\mathrm{ARF}} .^{24} \mathrm{p} 14^{\mathrm{ARF}}$ is a tumor suppressor that activates p53 and whose expression is impaired in most tumor cell lines retaining wild-type p53 including MCF7 and HCT116 cells. ${ }^{25}$ Overall, the effect of TSA on HDM2 mRNA was either very low or imperceptible and TSA-induced variations on endogenous hdm2 protein levels were negligible in comparison with the effects of TSA on p21 and pig3, as discussed below.

p53 weakens the positive effect of TSA on p21. In the case of P21 mRNA, TSA on its own clearly increased its levels in all cell lines tested (Figures 2, 3 and 5 and Supplementary Figures $\mathrm{S} 1$ and S6). Interestingly, the increase in P21 mRNA and protein levels by TSA was

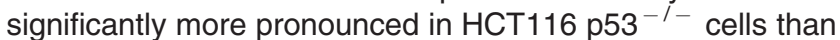

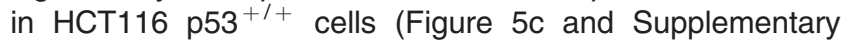
Figure S2). It has been described previously that TSA is able to induce p21 expression by increasing the levels of acetylated p300. ${ }^{11}$ p300 is an acetyltransferase that becomes activated upon acetylation and is involved in the activation of transcription of a large number of genes (reviewed in Chen and $\mathrm{Li}^{26}$ ). It has further been shown that activation of p300 by TSA leads to cooperation between this protein and the transcription factors $\mathrm{Sp} 1$ and $\mathrm{Sp} 3^{11}$ through another transcription factor, that is, ZBP-89 (BFCOL1/BERF-1/ZNF-148). Eventually, this complex activates $C D K N 1 A$ (p21) transcription in the absence of $p 53 .{ }^{10,12}$

Our data further indicate that TSA fails to increase P21 mRNA and protein levels in cells expressing wild-type p53 and treated with Nutlin-3 (Figures 2, 3 and 5 and Supplementary Figure S1). This suggests that active p53 prevents the ability of TSA to increase p21 expression. Another explanation may be that TSA's increasing effect on CDKN1A (p21) 

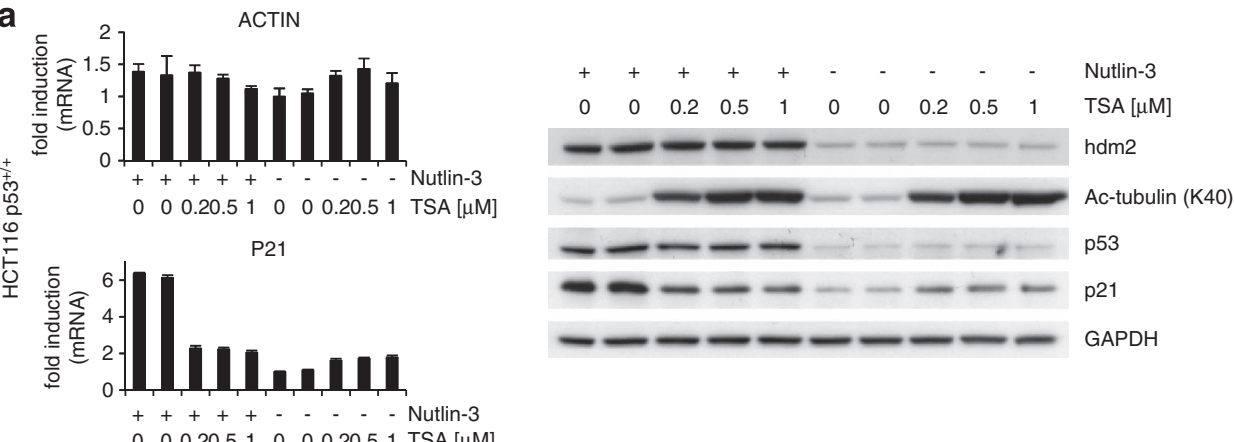

b
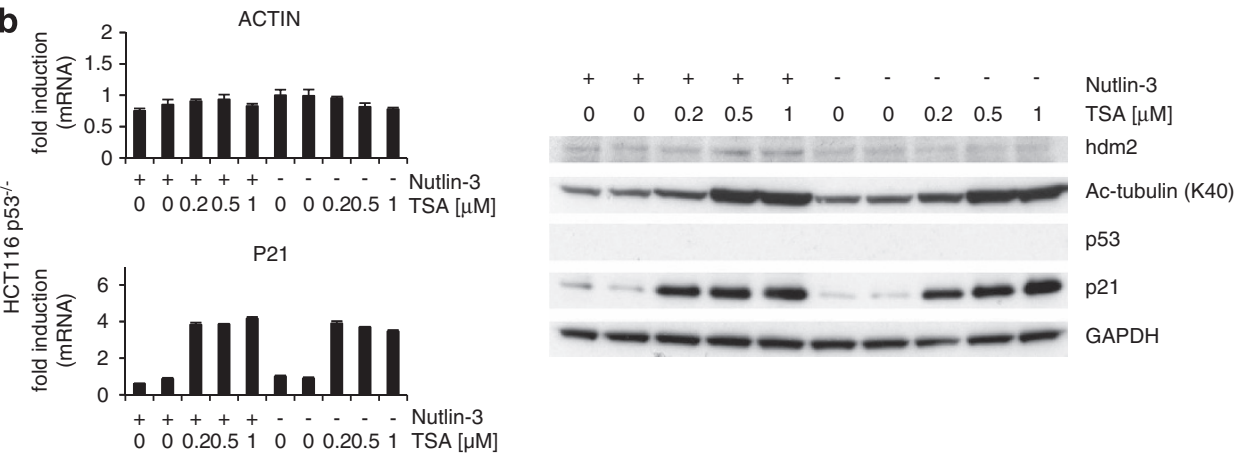

C
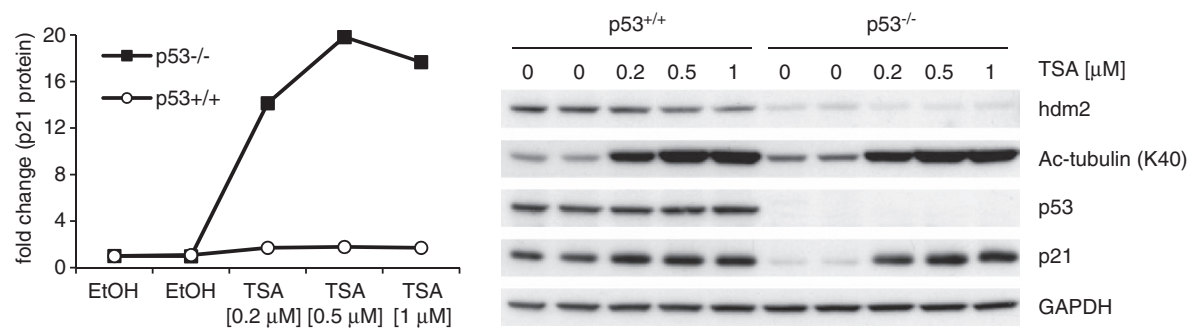

Figure 5 p53 reduces TSA's ability to activate p21 expression. (a) HCT116 p53 $3^{+/+}$and (b) $\mathrm{HCT116} \mathrm{p5} 3^{-/-}$cells were treated and analyzed as in Figure 2. (b) Acetylated $\alpha$-tubulin (K40) was used as control for TSA's activity and GAPDH as a loading control. (c) Error bars represent standard deviation. Graphs shown are representative of three independent experiments; the other two sets of data are shown in Supplementary Figures S1C and S1D, respectively. (c) HCT116 p53 ${ }^{+/+}$and $\mathrm{HCT} 116 \mathrm{p5} 3^{-1-}$ cells were treated with vehicle (EtOH) or various concentrations of TSA for $6 \mathrm{~h}$. Protein expression of p53 and p53 target genes were analyzed by western blotting (right panel); p21 protein levels were analyzed densitometrically (left panel)

transcription is linked to its ability to reduce c-myc levels, ${ }^{27,28}$ as c-myc can reduce p21 levels. ${ }^{29-32}$ Because p53, like TSA, represses the $C-M Y C$ promoter, ${ }^{33,34}$ further inhibition of c-myc expression by TSA could have no consequence.

TSA inhibits the effect of Nutlin-3 on p21. The previously reported reduction of $c$-myc levels by $\mathrm{TSA}^{27,28}$ may also explain why in the presence of TSA, Nutlin-3 fails to increase p21 levels further. Yet, this explanation is insufficient to understand why TSA markedly reduces P21 and PIG3 mRNA levels in the presence of Nutlin-3. As suggested above, TSA caused a small reduction in HDM2 mRNA levels in MCF7 and HCT116 cells cotreated with Nutlin-3 that could be explained by a small reduction in de novo synthesis of p53. However, although this small decrease in p53 synthesis by TSA may be the underlying cause, it is not sufficient to understand our observations on P21 and PIG3 mRNA levels, for which the negative effects of TSA in Nutlin-3 cotreated cells were much more pronounced. In a more extreme situation, that of HNDFs, HDM2 mRNA levels did not decrease at all, whereas P21 and PIG3 mRNAs were reduced substantially (Figure 3 ).

This selectivity could be due to a lower sensitivity of the HDM2 promoter to reductions in newly synthesized p53. To understand why the CDKN1A (p21) promoter would be more sensitive to a small reductions in p53 than the HDM2 promoter in nutlin-3-treated cells, we propose a model based on the two following reports: First, it has been shown that $C D K N 1 A$ and PIG3 promoters are bound by $\mathrm{p} 53$ and hdm2 and that the binding of hdm2 is associated with a reduction in the promoters' activity. In contrast, the HDM2 promoter is not bound by hdm2. ${ }^{32}$ Second, in the presence of Nutlin-3, HDM2 mRNA and protein levels are particularly high relative to other p53 downstream products. ${ }^{4}$ With this evidence, it is not unreasonable to suggest that the sharp hdm2 induction caused by Nutlin-3 may contribute in enhancing the TSA- 


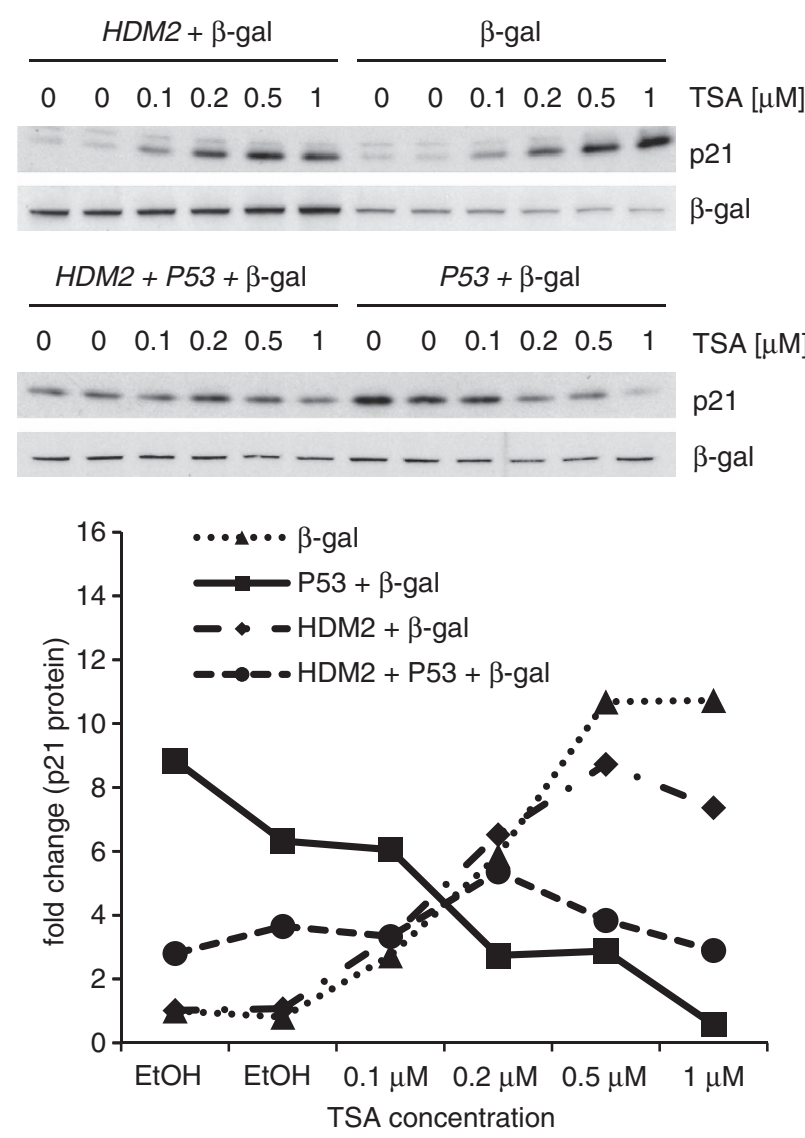

Figure 6 p53 inhibits the induction of p21 by TSA. H1299 (p53-null) cells were transfected with expression vectors encoding hdm2 and/or human p53. At $24 \mathrm{~h}$ post-transfection, cells were treated with TSA for $6 \mathrm{~h}$. All samples were transfected with a $\beta$-gal expression construct to assess sample loading and transfection efficiency. Protein levels were assessed by western blotting (upper two panels) and subsequent densitometric analysis (lower panel)

induced reduction in the expression of p53-dependent genes that are inhibited by hdm2, such as CDKN1A, but not HDM2. This interpretation could be extended to rationalize the negative effect of TSA on Nutlin-3-induced PIG3 mRNA. However, in this case, it must be kept in mind that TSA may have a negative effect on PIG3 mRNA expression regardless of the presence of p53. Note that a reduction in PIG3 mRNA levels by TSA also occurs in HCT116 cells where p53 is depleted (Supplementary Figure S7).

TSA is the only small-molecule p53 inhibitor with known targets. Pifithrins- $\alpha$ and $-\mu$ (reviewed in Gudkov and Komarova ${ }^{35}$ ) are two examples of small molecules that reduce p53 activity. However, the targets for pifithrins are still unknown. Instead, the mode of action of TSA is wellcharacterized. Even so, because TSA targets a wide range of HDACs involved in regulating a myriad of factors, understanding exactly how TSA treatment leads to a reduction in the expression of p53-dependent genes in cells cotreated with Nutlin-3 is a difficult task. Nevertheless, our work makes TSA the only compound inactivating p53 for which there is an established mode of action.
Implications for cancer therapy. From a cancer therapy perspective, our observations on the incompatible effects of TSA and Nutlin-3 on p21 expression may be of relevance when evaluating regimens where HDAC inhibitors and mdm2/p53-binding antagonists are combined. On the one hand, the results presented here could suggest that treatment of p53 wild-type tumor cells with an HDAC inhibitor could weaken the antitumor effect of Nutlin-3 and vice versa. On the other hand, it could be argued that by diminishing P21 mRNA levels, TSA could reduce Nutlin-3's cytostatic effect and increase the proportion of cells undergoing apoptosis. However, this interpretation is debatable, as it has been shown that p21 does not necessarily protect cancer cells from apoptosis induced by Nutlin-3. ${ }^{14}$ In any case, our results show that even if Nutlin-3 and TSA may weaken each others' effects in the short-term, long-term cotreatment of HCT116 p53 ${ }^{+/+}$cells with Nutlin-3 and TSA is still more toxic than either treatment on its own (Figure $8 \mathrm{c}$ ). This is very different from experiments where Nutlin-3 treatment clearly protects HCT116 ${\mathrm{p} 53^{+/+}}^{+}$cells from the S-phase and mitotic poisons. ${ }^{19-23}$

Relevance for the generation of induced pluripotent stem cells. Another interesting feature of TSA is that it increases efficiency in protocols to obtain induced pluripotent stem cells (iPS cells). ${ }^{36}$ Most likely, this is due to the effects of TSA on histone acetylation and removal of epigenetic inhibition of stem cell genes and pluripotency-associated genes. ${ }^{37}$ Our results suggest that part of TSA's positive effect in iPS cell protocols could be due to its ability to reduce the activity of p53. This is of relevance as it has been shown by four independent labs that deletion of p53 substantially increases efficiency in iPS cell protocols (reviewed in Okita and Yamanaka ${ }^{38}$ ). In this regard, it is worth noting that the expression of pluripotency genes OCT4, SOX2, C-MYC and KLF4 used to obtain iPS cells induces p53 and p21 levels. ${ }^{39}$ However, and even if treatment with TSA (unlike genetic deletion of P53) is not permanent, it must be borne in mind that the ability of TSA to reduce $\mathrm{p} 53$ transcription factor function could also contribute to genomic abnormalities in iPS cell cultures.

\section{Materials and Methods}

Cell culture. ARN8 cells, ${ }^{40}$ MCF7 cells (ATCC, Teddington, UK) and HNDFs (no. C-12300; PromoCell, Heidelberg, Germany) were cultured in DMEM supplemented with $10 \% \mathrm{FBS}$ and $1 \%$ penicillin/streptomycin (P/S). H1299 cells (ATCC) were grown in RPMI-1640 medium supplemented with 10\% FBS and $1 \%$ $\mathrm{P} / \mathrm{S}$. HCT116 $\mathrm{p5}^{+/+}$and HCT116 $\mathrm{p} 53^{-/-}$cells (a kind gift from B Vogelstein ${ }^{41}$ ) were cultured in McCoy's $5 \mathrm{~A}$ medium supplemented with $10 \% \mathrm{FBS}, 1 \% \mathrm{P} / \mathrm{S}$ and $3 \mathrm{mM}$ L-glutamine.

Reagents and antibodies. Nutlin-3 (no. N6287), TSA (no. T8552), formaldehyde (no. F1635), ribonuclease A (RNase A; no. R4642), Giemsa solution (no. 32884) and bovine serum albumin (BSA; no. 9647) were obtained from Sigma-Aldrich (Heidelberg, Germany). Chlorophenol red- $\beta$-D-galactopyranoside (CPRG; no. 884308) and FuGene 6 (no. 12454000) were purchased from Roche (Mannheim, Germany). Propidium iodide (PI; no. P3566) was obtained from Invitrogen (Eugene, OR, USA).

Antibodies used for western blotting were as follows: anti-Ac-p53 (K382) (no. 61420; BioLegend, London, UK), anti-actin (no. CP01; Calbiochem, Darmstadt, Germany), anti- $\beta$-galactosidase ( $\beta$-gal) (no. ОВ02; Calbiochem), anti-glyceraldehyde 3-phosphate dehydrogenase (GAPDH; no. 10R-G109a; Fitzgerald, Acton, MA, USA), anti-hdm2 (4B2; a kind gift from David P Lane), ${ }^{42}$ anti-noxa (no. 

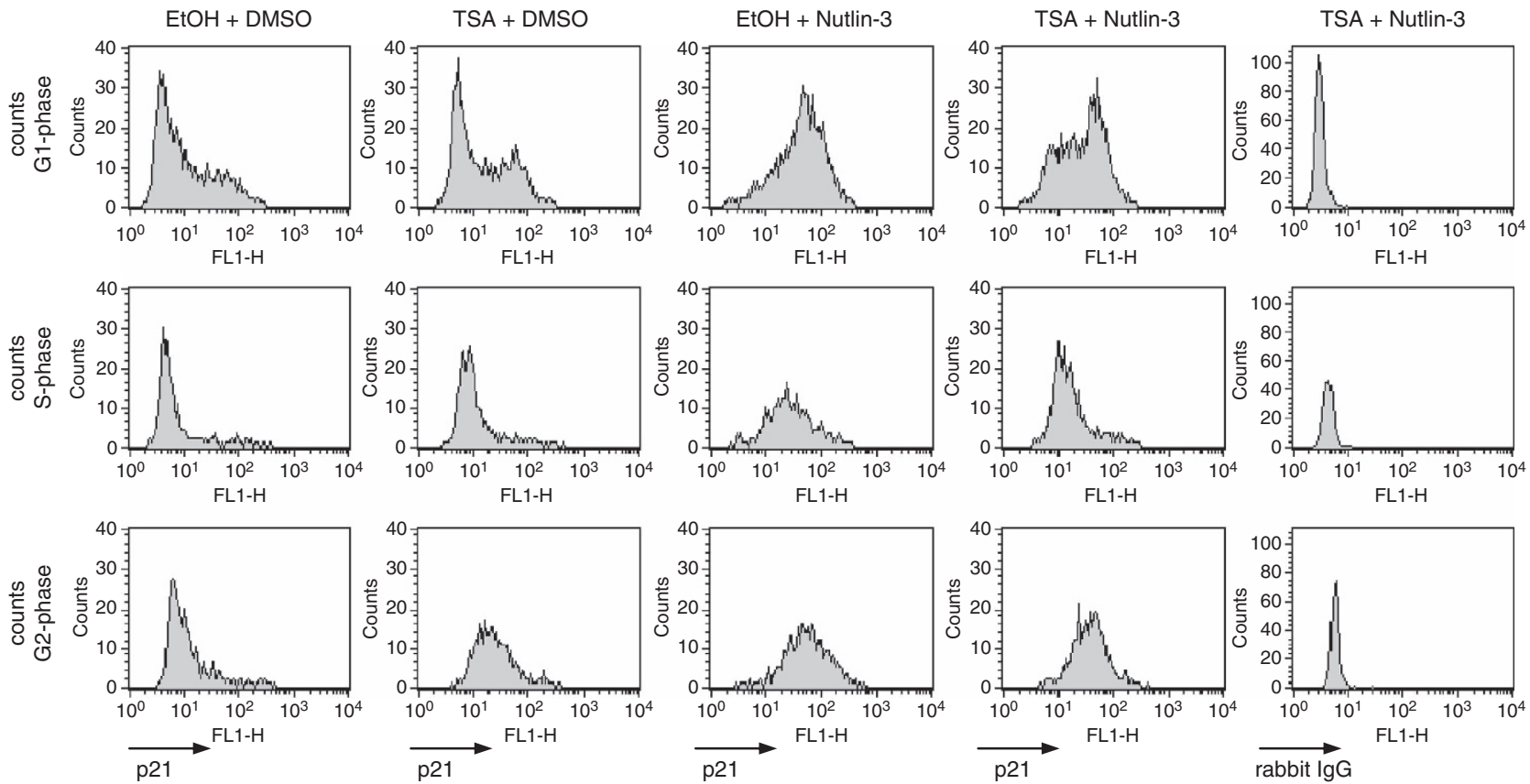

Figure 7 Nutlin-3 increases p21 levels during all phases of the cell cycle, whereas TSA increases p21 in cells during the G1 and G2 phase. MCF7 cells were subjected to short-term treatment with TSA $(0.5 \mu \mathrm{M})$ and/or Nutlin-3 $(5 \mu \mathrm{M})$ as indicated in Figure 2a. Fixed cells were incubated with an antibody against p21 (first four columns) or rabbit $\lg \mathrm{G}$ (fifth column), respectively, stained with PI and subjected to flow cytometric analysis

ab13654; Abcam, Cambridge, UK), anti-p21 (118; a kind gift from David P Lane), ${ }^{43}$ anti-p53 (DO-1; a kind gift from David P Lane) ${ }^{44}$ and anti-pig3 (no. sc-2020; Santa Cruz Biotechnology, Heidelberg, Germany). Secondary antibodies used for western blotting were horseradish peroxidase (HRP)-conjugated rabbit anti-mouse (no. P0161; Dako, Glostrup, Denmark) and HRP-conjugated swine anti-rabbit (no. P0217; Dako). Antibodies used for flow cytometry were anti-5bromo-2'-deoxyuridine (BrdU; no. 347580; Becton Dickinson, Franklin Lakes, $\mathrm{NJ}$, USA), fluorescein isothiocyanate-conjugated sheep anti-mouse (no. F3008; Sigma-Aldrich), Alexa Fluor 488-conjugated anti-p21 (no. 5487; Cell Signaling, Danvers, MA, USA) and Alexa Fluor 488-conjugated rabbit IgG (no. 4340; Cell Signaling).

p53-dependent transcription measurements. ARN8 cells expressing ( $\beta$-gal) under the control of a p53-dependent promoter (RGC $\Delta$ FosLacZ) were assayed as described previously. ${ }^{45}$ MCF7 cells were transiently transfected using FuGene 6 with both a plasmid containing the RGC $\Delta$ Fos-LacZ construct $^{46}$ and a plasmid encoding either Renilla or firefly luciferase; the latter two are driven by the SV40 promoter. After incubation with compounds for $24 \mathrm{~h}$, cells were lysed and $\beta$-gal activity detected using CPRG as a substrate. ${ }^{45}$ To measure luciferase activity, MCF7 cells were lysed with $1 \times$ Reporter Lysis Buffer (no. E397A; Promega, Madison, WI, USA), equal volumes of substrate from the DualLuciferase Reporter Assay System (no. E1960; Promega) added and luminescence measured on a Microplate Luminometer LB 96V (EG \& G Berthold, Bad Wildbad, Germany). RNA preparation and quantitative reverse transcriptionpolymerase chain reaction (quantitative RT-PCR) analysis were performed as described previously. ${ }^{4}$

Western blotting. Samples were prepared as described previously ${ }^{4}$ and run on 4-12\% precast gels (nos. NP0321 and NP0322; Invitrogen) according to the manufacturer's instructions. Proteins were transferred onto polyvinylidene difluoride membranes (no. IPVH00010; Millipore, Billerica, MA, USA) and developed by standard procedures. Levels of scanned films (no. 28906837; GE Healthcare, Buckinghamshire, UK) were adjusted in Adobe Photoshop CS4 Extended in accordance with the instructions given by this journal. P21 levels were analyzed densitometrically with Adobe Photoshop CS4 Extended using unmodified pictures of scanned films.
Cell cycle analysis. Two-dimensional flow cytometry for BrdU and PI was performed as described previously. ${ }^{23}$

Analysis of p21 expression during the cell cycle. Changes in p21 expression during different phases of the cell cycle were assessed by two-dimensional flow cytometry as follows: MCF7 cells were seeded in 6well plates and treated as indicated. Afterwards, cells were collected following trypsinization (including floating cells) and spun down at 2500 r.p.m. for $5 \mathrm{~min}$ at room temperature (RT). Cell pellets were resuspended in PBS and crosslinked with formaldehyde. Cells were fixed for $10 \mathrm{~min}$ at $37^{\circ} \mathrm{C}$ and subsequently chilled on ice for $1 \mathrm{~min}$. To permeabilize cells, methanol was added to a final concentration of $90 \%$. Cells were incubated for $30 \mathrm{~min}$ on ice and subsequently stored at $-20^{\circ} \mathrm{C}$ overnight. Later, cells were spun down at 2500 r.p.m. for $5 \mathrm{~min}$ at RT. Pellets were washed two times in incubation buffer (0.5\% BSA in PBS) and spun down at 2500 r.p.m. for $5 \mathrm{~min}$ at RT. Samples were blocked in incubation buffer for $10 \mathrm{~min}$ at RT and an Alexa Fluor 488-conjugated p21 antibody or an Alexa Fluor 488-conjugated control rabbit IgG added. After incubating for $1 \mathrm{~h}$ at RT in the dark, incubation buffer was added and cells were spun down at 2500 r.p.m. for $5 \mathrm{~min}$ at RT. Cell pellets were resuspended in PBS containing $50 \mu \mathrm{g} / \mu \mathrm{l}$ RNase A and incubated for $1 \mathrm{~h}$ at RT in the dark. Finally, cells were stained with $25 \mu \mathrm{g} / \mathrm{ml} \mathrm{PI}$. Flow cytometry was performed using a Becton Dickinson FACScan and results analyzed using the BD CellQuest Pro software (San Jose, CA, USA).

Clonogenic assays. For clonogenic assays, cells were seeded in 6-well plates and treated as indicated. Afterwards, cells were washed with growth medium and allowed to grow for 9 to 14 days. Subsequently, cells were fixed with methanolacetone $(1: 1)$ at $-20^{\circ} \mathrm{C}$ for $10 \mathrm{~min}$ to overnight and stained with Giemsa solution for 5-8 min at RT. The area occupied by cell colonies was quantified by using the ImageJ software (National Institute of Mental Health, Bethesda, MD, USA). Brightness and contrast of scanned plates were adjusted in Adobe Photoshop CS4 Extended in accordance with the instructions given by this journal.

Statistical analysis. Statistically significant differences between samples were determined by using an unpaired two-tailed Student's $t$-test. 
a

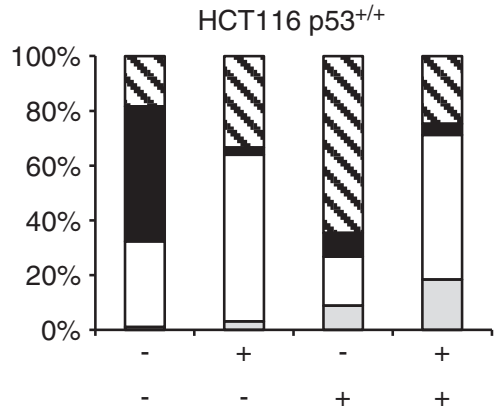

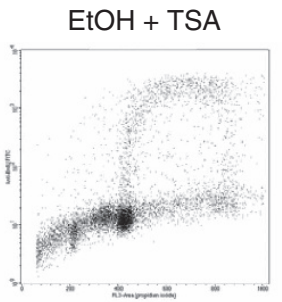
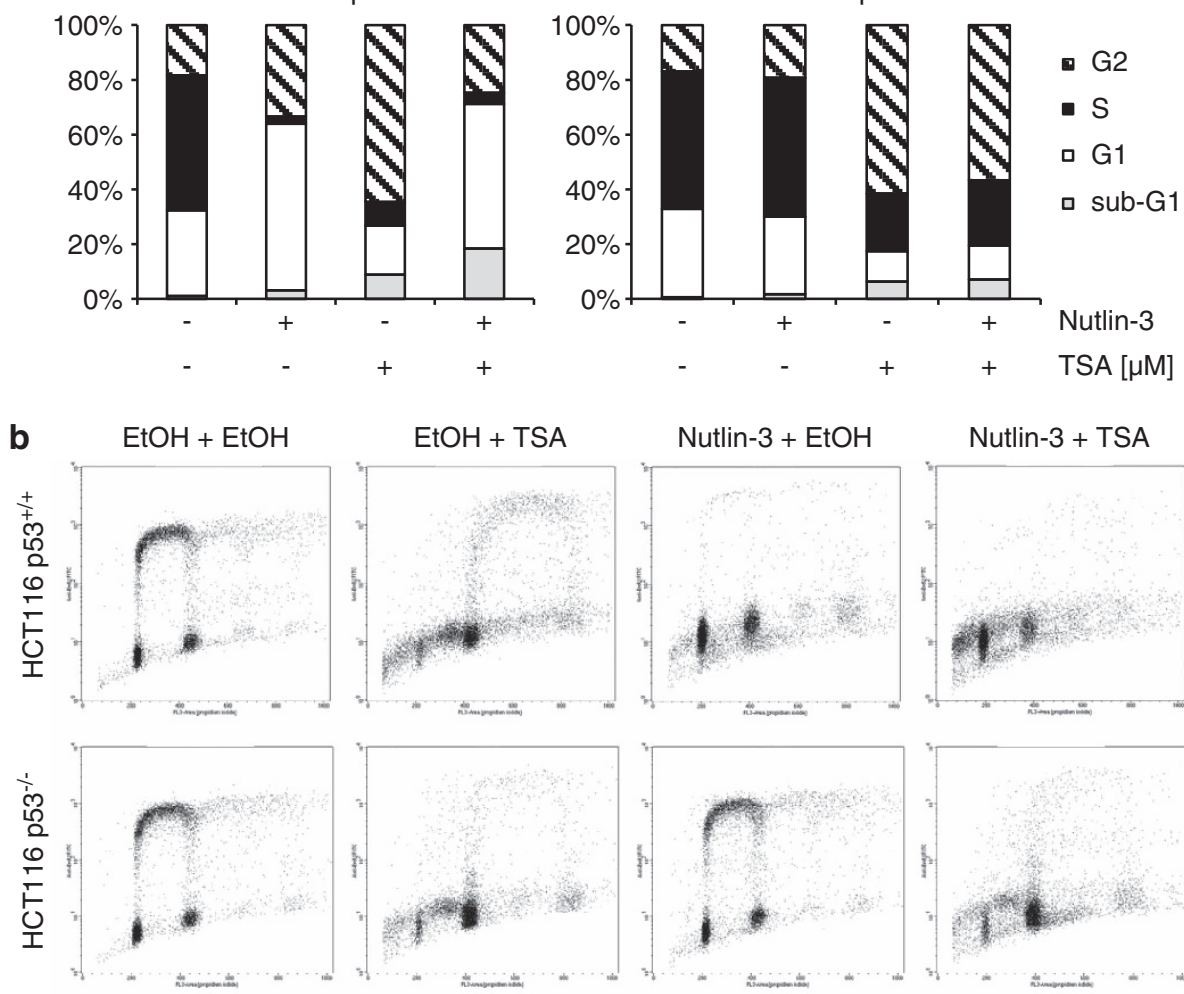

C
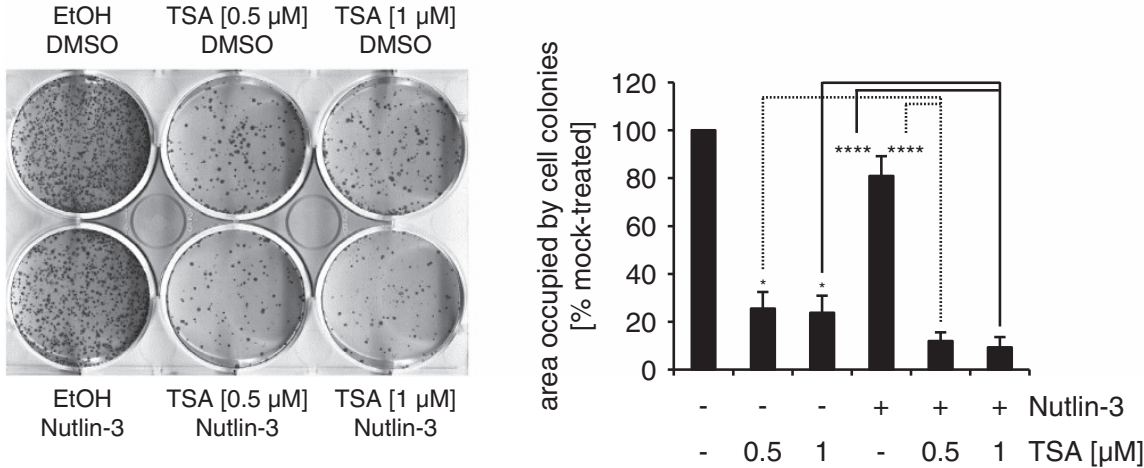

Figure 8 Nutlin-3 reduces TSA's ability to cause G2/M arrest and endoreduplication in tumor cells but does not protect tumor cells from TSA-mediated cytotoxicity. (a and

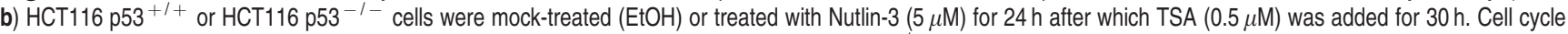
distribution was determined by two-dimensional flow cytometry for BrdU and PI. (c) HCT116 p53 $3^{+1+}$ cells were treated for $24 \mathrm{~h}$ with TSA and/or Nutlin-3 $(5 \mu \mathrm{M})$, the latter being added $1 \mathrm{~h}$ after TSA treatment. Afterwards, cells were washed with growth medium and allowed to grow for 9 days. Fixed cells were stained with Giemsa solution. The histogram shows plate area occupied by cell colonies as quantified in ImageJ; plate area occupied by mock-treated cells was set at $100 \%$. Error bars represent standard deviation of three independent experiments. ${ }^{*} P<0.05 ;{ }^{* \star \star} P<0.001$ (unpaired two-tailed Student's $t$-test; $n=3$ )

\section{Conflict of Interest}

The authors declare no conflict of interest.

Acknowledgements. We gratefully acknowledge Erik Fredlund for assistance in statistical analysis. This work was funded by grants from the Swedish Cancer Society (Cancerfonden), the Swedish Research Council (Vetenskapsrådet), the Association for International Cancer Research (AICR; Grant no. 10-0043) and Cancer Research UK (Grant no. C8/A6613) to SL. MS is the recipient of a PhD grant from Karolinska Institutet.

\section{Author contributions}

$\mathrm{MS}, \mathrm{CD}, \mathrm{MH}$ and $\mathrm{JC}$ performed experiments; $\mathrm{CD}$ contributed to discussion of data; MS and SL discussed and analyzed the data, and wrote the manuscript; and SL conceived the idea for the study and planned the experiments.

1. Marks PA, Breslow R. Dimethyl sulfoxide to vorinostat: development of this histone deacetylase inhibitor as an anticancer drug. Nat Biotechnol 2007; 25: 84-90.

2. Vassilev LT, Vu BT, Graves B, Carvajal D, Podlaski F, Filipovic Z et al. In vivo activation of the p53 pathway by small-molecule antagonists of MDM2. Science 2004; 303: 844-848.

3. Cheok CF, Dey A, Lane DP. Cyclin-dependent kinase inhibitors sensitize tumor cells to nutlin-induced apoptosis: a potent drug combination. Mol Cancer Res 2007; 5: $1133-1145$

4. van Leeuwen IM, Higgins M, Campbell J, Brown CJ, McCarthy AR, Pirrie L et al. Mechanism-specific signatures for small-molecule p53 activators. Cell Cycle 2011; 10: $1590-1598$. 
5. Peltonen K, Kivihariu TM, Jarvinen PM, Ra R, Laiho M. Melanoma cell lines are susceptible to histone deacetylase inhibitor TSA provoked cell cycle arrest and apoptosis. Pigment Cell Res 2005; 18: 196-202

6. Gialitakis M, Kretsovali A, Spilianakis C, Kravariti L, Mages J, Hoffmann R et al. Coordinated changes of histone modifications and HDAC mobilization regulate the induction of MHC class II genes by trichostatin A. Nucleic Acids Res 2006; 34: 765-772.

7. Blagosklonny MV, Robey R, Sackett DL, Du L, Traganos F, Darzynkiewicz Z et al. Histone deacetylase inhibitors all induce p21 but differentially cause tubulin acetylation, mitotic arrest, and cytotoxicity. Mol Cancer Ther 2002; 1: 937-941.

8. Suzuki T, Yokozaki H, Kuniyasu H, Hayashi K, Naka K, Ono S et al. Effect of trichostatin A on cell growth and expression of cell cycle- and apoptosis-related molecules in human gastric and oral carcinoma cell lines. Int J Cancer 2000; 88: 992-997.

9. Wu P, Meng L, Wang H, Zhou J, Xu G, Wang S et al. Role of hTERT in apoptosis of cervical cancer induced by histone deacetylase inhibitor. Biochem Biophys Res Commun 2005; 335: $36-44$.

10. Sowa $\mathrm{Y}$, Orita T, Hiranabe-Minamikawa S, Nakano K, Mizuno T, Nomura $\mathrm{H}$ et al. Histone deacetylase inhibitor activates the p21/WAF1/Cip1 gene promoter through the Sp1 sites. Ann NY Acad Sci 1999; 886: 195-199.

11. Xiao H, Hasegawa T, Isobe K. P300 collaborates with Sp1 and Sp3 in p21(waf1/cip1) promoter activation induced by histone deacetylase inhibitor. J Biol Chem 2000; 275 : 1371-1376.

12. Xiao $\mathrm{H}$, Hasegawa $\mathrm{T}$, Isobe $\mathrm{K}$. Both $\mathrm{Sp} 1$ and $\mathrm{Sp} 3$ are responsible for $\mathrm{p} 21$ waf1 promoter activity induced by histone deacetylase inhibitor in NIH3T3 cells. J Cell Biochem 1999; 73: 291-302.

13. Oda E, Ohki R, Murasawa H, Nemoto J, Shibue T, Yamashita T et al. Noxa, a BH3-only member of the Bcl-2 family and candidate mediator of p53-induced apoptosis. Science 2000; 288: 1053-1058.

14. Xia M, Knezevic D, Vassilev LT. P21 does not protect cancer cells from apoptosis induced by nongenotoxic p53 activation. Oncogene 2011; 30: 346-355.

15. Kemp MG, Ghosh M, Liu G, Leffak M. The histone deacetylase inhibitor trichostatin A alters the pattern of DNA replication origin activity in human cells. Nucleic Acids Res 2005; 33 : 325-336.

16. Bickmore WA, Carothers AD. Factors affecting the timing and imprinting of replication on a mammalian chromosome. J Cell Sci 1995; 108(Part 8): 2801-2809.

17. Noh EJ, Lim DS, Jeong G, Lee JS. An HDAC inhibitor, trichostatin A, induces a delay at G2/ $\mathrm{M}$ transition, slippage of spindle checkpoint, and cell death in a transcription-dependent manner. Biochem Biophys Res Commun 2009; 378: 326-331.

18. Furumai R, Komatsu Y, Nishino N, Khochbin S, Yoshida M, Horinouchi S. Potent histone deacetylase inhibitors built from trichostatin $A$ and cyclic tetrapeptide antibiotics including trapoxin. Proc Natl Acad Sci USA 2001; 98: 87-92.

19. Carvajal D, Tovar C, Yang H, Vu BT, Heimbrook DC, Vassilev LT. Activation of p53 by MDM2 antagonists can protect proliferating cells from mitotic inhibitors. Cancer Res 2005; 65: 1918-1924.

20. Kranz D, Dobbelstein M. Nongenotoxic p53 activation protects cells against S-phasespecific chemotherapy. Cancer Res 2006; 66: 10274-10280.

21. Sur S, Pagliarini R, Bunz F, Rago C, Diaz LA Jr., Kinzler KW et al. A panel of isogenic human cancer cells suggests a therapeutic approach for cancers with inactivated p53. Proc Natl Acad Sci USA 2009; 106: 3964-3969.

22. Cheok CF, Kua N, Kaldis P, Lane DP. Combination of nutlin-3 and VX-680 selectively targets p53 mutant cells with reversible effects on cells expressing wild-type p53. Cell Death Differ 2010; 17: 1486-1500.

23. van Leeuwen IM, Rao B, Sachweh MC, Lain S. An evaluation of small-molecule p53 activators as chemoprotectants ameliorating adverse effects of anti-cancer drugs in normal cells. Cell Cycle 2012; 11: 1851-1861.

24. Matheu A, Klatt $P$, Serrano M. Regulation of the INK4a/ARF locus by histone deacetylase inhibitors. J Biol Chem 2005; 280: 42433-42441.

25. Stott FJ, Bates S, James MC, McConnell BB, Starborg M, Brookes S et al. The alternative product from the human CDKN2A locus, p14(ARF), participates in a regulatory feedback loop with p53 and MDM2. EMBO J 1998; 17: 5001-5014.

26. Chen J, Li Q. Life and death of transcriptional co-activator p300. Epigenetics 2011; 6 : 957-961.

27. Li $H$, Wu X. Histone deacetylase inhibitor, trichostatin A, activates p21WAF1/CIP1 expression through downregulation of c-myc and release of the repression of c-myc from the promoter in human cervical cancer cells. Biochem Biophys Res Commun 2004; 324 : 860-867.

28. Weber A, Liu J, Collins I, Levens D. TFIIH operates through an expanded proximal promoter to fine-tune c-myc expression. Mol Cell Biol 2005; 25: 147-161.

29. Mitchell KO, El-Deiry WS. Overexpression of c-Myc inhibits p21WAF1/CIP1 expression and induces S-phase entry in 12-0-tetradecanoylphorbol-13-acetate (TPA)-sensitive human cancer cells. Cell Growth Differ 1999; 10: 223-230.

30. Claassen GF, Hann SR. A role for transcriptional repression of p21CIP1 by c-Myc in overcoming transforming growth factor beta -induced cell-cycle arrest. Proc Natl Acad Sci USA 2000; 97: 9498-9503.

31. Coller HA, Grandori C, Tamayo P, Colbert T, Lander ES, Eisenman RN et al. Expression analysis with oligonucleotide microarrays reveals that MYC regulates genes involved in growth, cell cycle, signaling, and adhesion. Proc Natl Acad Sci USA 2000; 97: $3260-3265$.

32. Gartel AL, Ye X, Goufman E, Shianov P, Hay N, Najmabadi F et al. Myc represses the p21(WAF1/CIP1) promoter and interacts with Sp1/Sp3. Proc Natl Acad Sci USA 2001; 98 : 4510-4515.

33. Ragimov N, Krauskopf A, Navot N, Rotter V, Oren M, Aloni Y. Wild-type but not mutant p53 can repress transcription initiation in vitro by interfering with the binding of basal transcription factors to the TATA motif. Oncogene 1993; 8: 1183-1193.

34. Yonish-Rouach E, Grunwald D, Wilder S, Kimchi A, May E, Lawrence JJ et al. P53-mediated cell death: relationship to cell cycle control. Mol Cell Biol 1993; 13 1415-1423.

35. Gudkov AV, Komarova EA. Dangerous habits of a security guard: the two faces of $\mathrm{p} 53$ as a drug target. Hum Mol Genet 2007; 16: R67-R72.

36. Huangfu D, Maehr R, Guo W, Eijkelenboom A, Snitow M, Chen AE et al. Induction of pluripotent stem cells by defined factors is greatly improved by small-molecule compounds. Nat Biotechnol 2008; 26: 795-797.

37. Ruau D, Ensenat-Waser R, Dinger TC, Vallabhapurapu DS, Rolletschek A, Hacker C et al. Pluripotency associated genes are reactivated by chromatin-modifying agents in neurosphere cells. Stem Cells 2008; 26: 920-926.

38. Okita K, Yamanaka S. Induced pluripotent stem cells: opportunities and challenges. Philos Trans R Soc Lond Ser B 2011; 366: 2198-2207.

39. Kawamura T, Suzuki J, Wang YV, Menendez S, Morera LB, Raya A et al. Linking the p53 tumour suppressor pathway to somatic cell reprogramming. Nature 2009; 460: 1140-1144.

40. Blaydes JP, Hupp TR. DNA damage triggers DRB-resistant phosphorylation of human p53 at the CK2 site. Oncogene 1998; 17: 1045-1052.

41. Bunz F, Dutriaux A, Lengauer C, Waldman T, Zhou S, Brown JP et al. Requirement for p53 and p21 to sustain G2 arrest after DNA damage. Science 1998; 282: 1497-1501.

42. Chen J, Marechal V, Levine AJ. Mapping of the p53 and mdm-2 interaction domains. Mol Cell Biol 1993; 13: 4107-4114.

43. Fredersdorf S, Milne AW, Hall PA, Lu X. Characterization of a panel of novel anti-p21Waf1/ Cip1 monoclonal antibodies and immunochemical analysis of p21Waf1/Cip1 expression in normal human tissues. Am J Pathol 1996; 148: 825-835.

44. Vojtesek B, Bartek J, Midgley CA, Lane DP. An immunochemical analysis of the human nuclear phosphoprotein p53. New monoclonal antibodies and epitope mapping using recombinant p53. J Immunol Methods 1992; 151: 237-244.

45. Berkson RG, Hollick JJ, Westwood NJ, Woods JA, Lane DP, Lain S. Pilot screening programme for small molecule activators of p53. Int J Cancer 2005; 115: 701-710.

46. Frebourg T, Barbier $\mathrm{N}$, Kassel J, Ng YS, Romero P, Friend SH. A functional screen for germ line p53 mutations based on transcriptional activation. Cancer Res 1992; 52: 6976-6978.

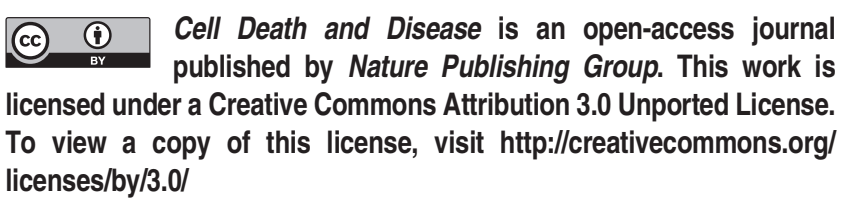

